WellBeing International

WBI Studies Repository

3-1985

\title{
Visual Evoked Potentials in the Great Apes
}

Sarah T. Boysen

Ohio State University

Gary G. Berntson

Ohio State University

Follow this and additional works at: https://www.wellbeingintlstudiesrepository.org/acwp_asie

Part of the Animal Studies Commons, Other Animal Sciences Commons, and the Other Veterinary Medicine Commons

\section{Recommended Citation}

Boysen, S. T., \& Berntson, G. G. (1985). Visual evoked potentials in the great apes. Electroencephalography and Clinical Neurophysiology/Evoked Potentials Section, 62(2), 150-153.

This material is brought to you for free and open access by WellBeing International. It has been accepted for inclusion by an authorized administrator of the WBI Studies Repository. For more information, please contact wbisr-info@wellbeingintl.org.

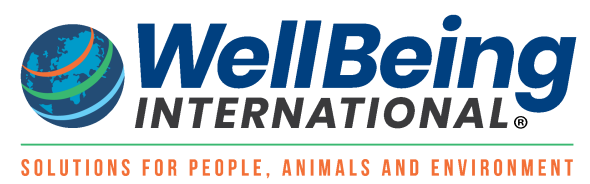




\title{
Visual Evoked Potentials in the Great Apes
}

\author{
Sarah T. Boysen and Gary G. Berntson \\ Ohio State University
}

Recent years have witnessed a resurgence of interest in animal cognition, bolstered in part by highly sophisticated and quantitative methodologies derived from the information processing literature (Thatcher and John 1977; Griffin 1981: Sands and Wright 1982). A complementary approach which offers considerable promise in the objective study of cognitive functions in animals is based on the documented relationships between brain event-related potentials (ERPs) and specific cognitive processes in the human (Donchin et at. 1978; Galambos and Hillyard 1981; Hillyard and Kutas 1983). Many of the topographic and functional properties of ERPs obtained from monkeys appear to parallel those of the human (Creel et al. 1973; Golf et al. 1978; Arezzo et al. 1981). Moreover, ERP components in nonhuman primates appear to share many of the same cognitive correlates of their apparent homologues in humans. For example, a P300 wave having functional properties highly similar to the P300 in humans has been reported in response to a task-relevant stimulus in monkeys (Donchin et al. 1971; Arthur and Starr 1984). These findings suggest that the ERP methodology may provide a powerful tool for the investigation of cognitive dynamics in primate models.

In this regard, the Great Apes represent the extant species that may provide the closest parallel to human cognitive function. Biochemical and immunological similarities between the chimpanzee and the human are notable (King and Wilson 1975), and recent behavioral studies suggest that the chimpanzee may serve as an ideal animal model of human information processing (Premack 1983). Unfortunately, little is known concerning ERPs in apes. Adey et al. (1963) recorded flash-evoked potentials from the reticular formation in the chimpanzee, although scalp-recorded evoked potentials have not yet been described. In view of these considerations, we examined the form and development of scalp-recorded evoked potentials to photic stimuli in apes.

\section{Methods}

Visual evoked potentials (VEPs) to stroboscopic flash stimuli (20 $\mu$ sec duration, $0.7 \mathrm{~Hz}, 105 \mathrm{lux}$ ) were Obtained from 3 infant chimpanzees, 2 juvenile chimpanzees, and 1 infant gorilla. The infant chimpanzees ( 1 male and 2 females, 37 weeks of age) and the gorilla (male, 11 weeks) were tested at the Yerkes Regional Primate Research Center, and the 2 juvenile chimpanzees (males, 3 and 3.5 years) were tested at Ohio State University. Testing was accomplished in a darkened room (less than 1 lux), with the animals lying quietly in a supine position. VEP measures from the infants were obtained in the waking state, and juvenile animals were tested while lightly sedated with ketamine (14 mg/kg, s.c.; given in conjuction with routine TB testing). In addition, VEPs were obtained in the 4 infant animals during quiet sleep, although comprehensive studies of sleep stages were not pursued.

Gold cup electrodes were secured with standard collodion techniques to scalp sites Oz and Cz, and to A1 (reference) and A2 (ground). In addition, electrodes were applied at supraorbital and lateral canthal sites, for monitoring eye movements and eye blinks in unsedated animals. In all cases, electrode impedances were below $5 \mathrm{~kg}$. EEG and eye movement signals were amplified by a polygraph (1-90 $\mathrm{Hz}$ bandpass), and were then digitized on-line or recorded on FM tape for off-line analyses. Eight-bit digitization (2 msec dwell time, $512 \mathrm{msec}$ window) was accomplished by means of a signal processor, coupled to a 
microcomputer data acquisition system. For offline analyses, amplified signals were recorded and individual sweeps were subsequently digitized and stored for further processing.

EEG signals were averaged over 60 artifact-free traces, with 2 averages obtained under each condition. Traces with EEG signals exceeding $+/-60 \mu \mathrm{V}$ from baseline or eye movement signals over $+/-30 \mu \mathrm{V}$ were automatically excluded from further analysis (resulting in rejection of approximately $15 \%$ of the sweeps). Eye movement traces from the remaining sweeps were averaged along with the EEG channels to insure the effectiveness of the eye movement artifact rejection. In no case did averaged eye movement signals exceed $+/-3 \mu \mathrm{V}$.

TABLE 1. Latencies of consistently appearing waves of the VER in apes.

\begin{tabular}{|c|c|c|c|c|c|c|c|}
\hline \multirow[t]{2}{*}{ Subject } & \multirow[t]{2}{*}{ Age } & \multicolumn{3}{|c|}{$\mathrm{Oz}$ (msec) } & \multicolumn{3}{|c|}{ Cz (msec) } \\
\hline & & N60 & P90 & N110 & P70 & N125 & P225 \\
\hline Chimp $^{a}$ & $3 w k$ & 133 & 176 & 237 & --- & --- & --- \\
\hline Chimp $^{a}$ & $5 \mathrm{wk}$ & 111 & 168 & 195 & --- & --- & --- \\
\hline Chimp $^{a}$ & $7 \mathrm{wk}$ & 88 & 123 & 158 & --- & --- & --- \\
\hline Gorilla $^{a}$ & $11 \mathrm{wk}$ & 72 & 115 & 139 & 66 & 145 & 246 \\
\hline Chimp $^{b}$ & $3.0 \mathrm{yr}$ & 57 & 84 & 107 & 86 & 123 & 236 \\
\hline Chimp $^{b}$ & $3.5 \mathrm{yr}$ & 62 & 90 & 112 & 66 & 106 & 199 \\
\hline
\end{tabular}

${ }^{a}$ Values obtained under waking conditions.

${ }^{\mathrm{b}}$ Tested after ketamine.

\section{Results}

All animals demonstrated robust VEPs at occipital scalp sites (Fig. 1), which were generally comparable to those obtained in humans and monkeys (e.g., Ferris et al. 1967; Creel et al. 1973; Klorman et al. 1978; Snyder et al. 1979). A consistent feature of the wave forms was a prominent positive wave (P90) with a latency ranging from 84 to $176 \mathrm{msec}$ (Table 1). In contrast, there was considerable variation in the presence and form of later components across animals. A notable developmental trend was apparent in the N60, P90 and N110 waves, which showed a dramatically diminishing latency with increasing age (Table 1). It is possible that sedation may have altered the latencies of these waves somewhat for the two juvenile animals. Ketamine and related dissociative anesthetics, however, appear to have minimal effects on ERP latencies, at least for early and middle-latency components (Dafny and Rigor 1978; Cohen and Britt 1982; Matsuzaki and Dowling 1983). In any event, the developmental trend in wave latencies observed in the present study was readily apparent even among the unsedated animals.

In contrast to the consistent appearance of the VEP at the occipital site, responses from $\mathrm{Cz}$ were observed only in the older animals (Fig. 1). A common feature of these vertex responses was a notable negative-positive (N125-P225) complex, similar to the 'vertex wave' of the human (Bancaud et al. 1953; Goff et al. 1978). The appearance of vertex responses only in the older animals likely reflects a developmental trend, and is not spuriously related to a temporal smearing associated with exaggerated latency variability in the young animals. This is suggested by the lack of increased variance of the wave forms within the time window in which vertex responses would be expected in the younger animals (pointby-point S.D.s of the wave forms, calculated from the individual sweeps, averaged $6.0 \mu \mathrm{V}$ overall, and 6.0 $\mu \mathrm{V}$ within the $50-250 \mathrm{msec}$ window). 
Fig. 1. Visual evoked potentials to a flash stimulus recorded from occipital $(\mathrm{Oz})$ and vertex $(\mathrm{Cz})$ scalp sites, referenced to $A 1$. The ages of the animals are illustrated (in weeks or years) between the sets of tracings for each subject. Dashed lines illustrate the two independent averages of 60 stimuli each, and the solid lines show the overall average of 120 sweeps. Positivity is down.

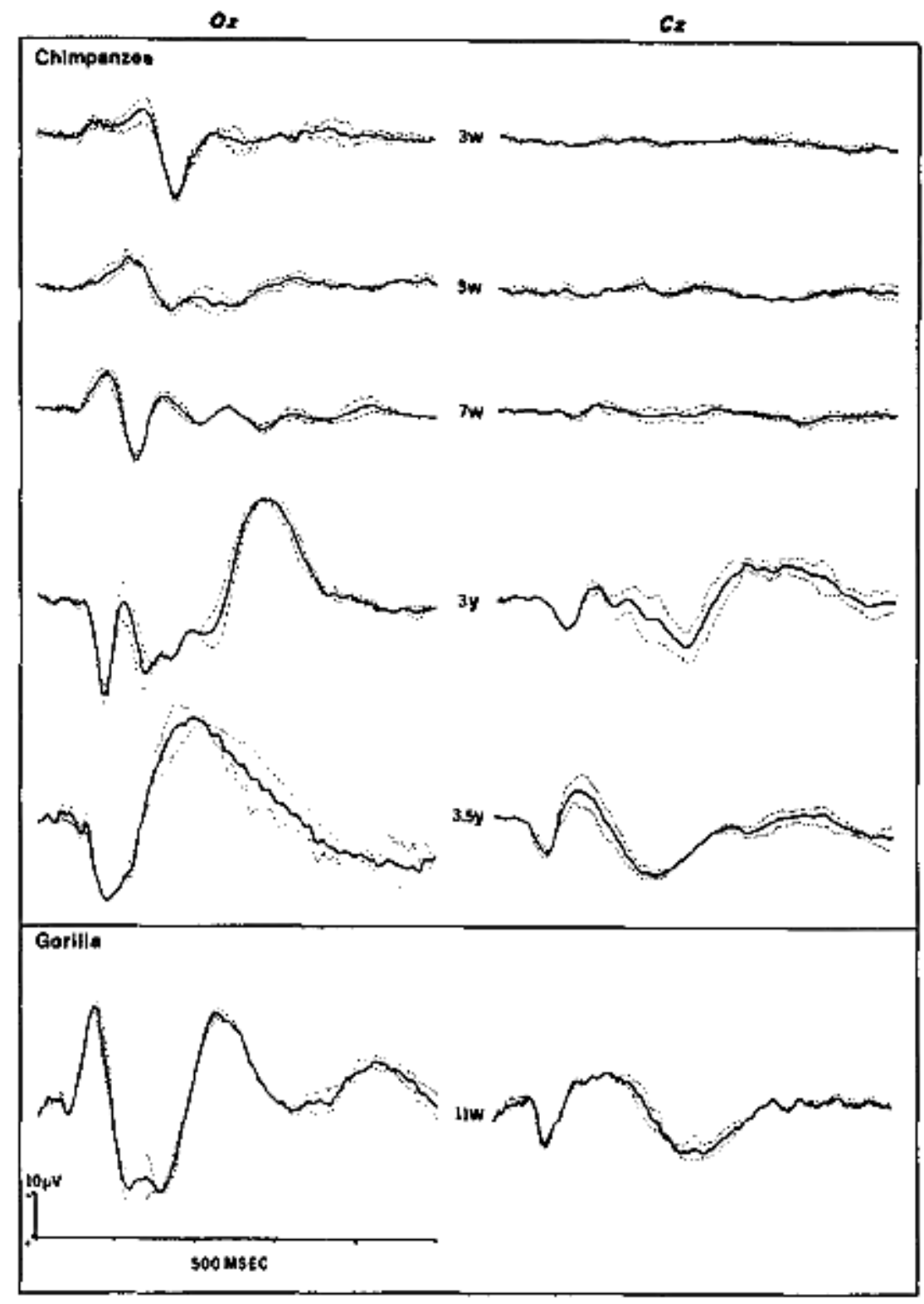

The wakeful EEG of the infants consisted of relatively low amplitude fast activity with irregular low amplitude slow waves (4-8 c/sec), typical of immature primates (Ellingson and Rose 1970; Ellingson 1975). VEPs in the infants were also obtained during sleep-onset episodes of quiet sleep, which were characterized by EEG sleep spindles (13-15 c/sec, maximal at Cz), interspersed with 3-6 c/sec slow waves of increased prominence. The evoked potentials obtained during sleep were generally quite similar to those obtained in the wakeful state, although wave latencies were somewhat longer during sleep (mean $=9.1 \mathrm{msec})$. 


\section{Discussion}

The present results represent the first characterization of scalp-recorded ERPs in the Great Apes. These responses were readily recordable by means of non-invasive surface electrodes and were generally similar to ERPs obtained from both humans and monkeys. In two respects, however, the present results are more similar to those reported for humans than for non-human primates. First, the developmental decrease in latency of the P90 wave observed in the present study is also highly characteristic of VEPs from the human (Ferris et al. 1967; Klorman et al. 1978). Indeed, the latencies of the P90 wave across the range of ages in the present study are virtually identical to the values generally reported for humans at corresponding ages. In contrast, monkeys appear to show age-related decreases in latencies only of later components of the ERP (Dustman et al. 1979). Secondly, the form of the vertex responses observed in the present study is reminiscent of that obtained from humans (Goff et al. 1978; Dustman and Snyder 1981), while such characteristic central scalp responses to photic stimuli are not readily apparent in the monkey (Goff et al. 1978; Snyder et al. 1979). Vertex responses in general have received considerable attention since they appear to be highly sensitive to cognitive/behavioral processes (Donchin et al. 1978; Galambos and Hillyard 1981; Hillyard and Kutas 1983).

The present findings fill an important gap in the comparative literature on ERPs and offer exciting prospects for the application of ERPs to the study of cognitive processes in the Great Apes.

\section{Summary}

Visual evoked potentials (VEPs) in response to flash stimuli were recorded from occipital and centralscalp electrodes in the chimpanzee and gorilla. The most notable occipital component of the VEP was a surface-positive wave (P90), the latency of which decreased with development. Central scalp responses, apparent only in older animals, included a characteristic long-latency 'vertex wave' (N125-P225). Observed responses are similar to those reported for humans and monkeys, but appear to share more specific features of human VEPs.

\section{Acknowledgments}

Supported by a grant from OSU, and by Grant RR-00165 from the $\mathrm{N} 1 \mathrm{H}$, Division of Research and Resources, Animal Resources Program, to the Yerkes Regional Primate Research Center, Emory University.

We thank Drs. F. King, L. Byrd, H. McClure and B. Swenson for facilitating this effort.

\section{References}

Adey, W.R., Kado, R.T. and Rhodes, J.M. Sleep: cortical and subcortical recordings in the chimpanzee. Science, 1963, 141: 932-933.

Arezzo, J.C., Pickoff, A. and Vaughan, H.G. Topography and intracranial sources of somatosensory evoked potentials in the monkey. II. Cortical components. Electroenceph. clin. Neurophysiol., 1981, 51: 1-18.

Arthur, D.L. and Starr, A. Task-relevant late positive component of the auditory event-related potential in monkeys resembles P300 in humans. Science, 1984, 223: 186-188.

Bancaud, J., Bloch, V. et Paillard, J. Contribution E.E.G. á l'értude des potentiels évoqués chez l'homme au niveau du vertex. Rev. neurol., 1953, 89: 183-192.

Cohen, M.S. and Britt, R.H. Effects of sodium pentobarbital, ketamine, halothane, and chloralose on brainstem auditory evoked responses. Anesth. Analg., 1982, 61: 338-343. 
Creel, D.J., Dustman, R.E. and Beck, C. Visually evoked responses in the rat, guinea pig, cat, monkey, and man. Exp. Neurol., 1973, 40: 351-366.

Dafny, N. and Rigor, B.M. Dose effects of ketamine on photic and acoustic field potentials. Neuropharmacology, 1978, 17: 851-862.

Donchin, E., Otto, D., Gerbrandt, L.K. and Pribram, K.H. While a monkey waits: electrocortical events recorded during the foreperiod of a reaction time study. Electroenceph. clin. Neurophysiol., 1971, 31: 115-127.

Donchin, E., Ritter, W. and McCallum, W.C. Cognitive psychophysiology: the endogenous components of the ERP. In: E. Callaway, P. Tueting and S.H. Koslow (Eds.), Event-Related Potentials in Man. Academic Press, New York, 1978: 349-441.

Dustman, R.E. and Snyder, E.W. Life-span changes in visually evoked potentials at central scalp. Neurobiol. Aging, 1981, 2: 303-308.

Dustman, R.E., Snyder, E.W., Creel, D. and Beck, E.C. Ontogeny of the visual evoked response in the stump-tailed macaque. Develop. Psychobiol., 1979, 12: 161-167.

Ellingson, R.J. Ontogenesis of sleep in humans. In: G.C. Lairy and P. Salzarulo (Eds.), Experimental Study of Human Sleep: Methodological Problems. Elsevier, Amsterdam, 1975: 129-149.

Ellingson, R.J. and Rose, G.H. Ontogenesis of the electroencephalogram. In: W.A. Himwich (Ed.), Developmental Neurobiology. Thomas, Springfield, IL, 1970: 441-474.

Ferris, G.S., Davis, G.D., Dorsen, M.McF. and Hackett, E.R. Changes in latency and form of the photically induced average evoked response in human infants. Electroenceph. clin. Neurophysiol., 1967, 22: 305-312.

Galambos,R . and Hillyard, S.A. Electrophysiological approaches to human cognitive processing. Neurosci. Res. Prog. Bull., 1981, 20: 141-248.

Goff, W.R., Allison, T. and Vaughan, H .G. The functional anatomy of event-related potentials. In: E. Callaway, P. Tueting and S.H. Koslow (Eds.), Event-Related potentials in Man. Academic Press, New York, 1978:5 11-570.

Griffin, D.R. The Question of Animal Awareness: Evolutionary Continuity of Mental Experience. Rockefeller Univ. Press, New York, 1981.

Hillyard, S.A. and Kutas, M. Electrophysiology of cognitive processing. Ann. Rev. Psychol., 1983, 34: 3261.

King, M.C. and Wilson, A.C. Evolution at two levels in humans and chimpanzees. Science, 1975, 188 : 107-116.

Klorman,R ., Thompson, L.W. and Ellingson, R .J. Event-related brain potentials across the life span. In: E. Callaway, P. Tueting and S.H. Koslow (Eds.), Event-Related Potentials in Man. Academic Press, New York, 1978: 511-570.

Matsuzaki, M. and Dowling, K.C. Effects of phencyclidine (PCP) on the visual evoked potentials in the rhesus monkey. Brain Res. Bull., 1983, 10: 33-38.

Premack D. The codes of man and beast. Behav. Brain Sci,, 1983, 6: 125-157.

Sands, S.F. and Wright, A.A. Monkey and human pictorial memory scanning. Science, 1982, 216: 13331334.

Snyder,E .W., Beck, E.C. and Dustman, R.E. Visual evoked potentials in monkeys. Electroenceph. clin. Neurophysiol., 1979, 47: 430-440.

Thatcher,R .W. and John, E.R. Foundations of Cognitive Processes. Lawrence Erlbaum, Hillsdale NJ, 1977. 